\title{
Role of amiodarone on the systemic inflammatory response induced by cardiac surgery: proinflammatory actions
}

\author{
[Rôle de l'amiodarone sur la réaction inflammatoire systémique provoquée par la
}

chirurgie cardiaque : actions pro-inflammatoires]

Georg Delle Karth MD, ${ }^{*}$ Anton Buberl MD, ${ }^{*}$ Mariam Nikfardjam MD, ${ }^{*}$ Brigitte Meyer MD, ${ }^{*}$

Gregor Wollenek MD, $\dagger$ Michael Grimm MD, $†$ Andrea Lassnigg MD, $\ddagger$ Werner Brannath PhD,,

Michael Hiesmayr MD, $\ddagger$ Gottfried Heinz MD*

Purpose: Amiodarone (AMIO), a widely used anti-arrhythmic drug, has been shown to reduce the incidence of atrial fibrillation after cardiac surgery and also to exert immunomodulatory actions in vitro and proinflammatory effects in vivo. The present study investigated the immunomodulatory properties of AMIO in the inflammatory response induced by cardiac surgery with cardiopulmonary bypass (CPB).

Methods: In this double-blind, placebo-controlled trial, 20 patients undergoing elective coronary artery bypass graft were randomized to receive placebo or AMIO $600 \mathrm{mg} \cdot$ day $^{-1}$ orally for seven days before surgery and $45 \mathrm{mg} \cdot \mathrm{hr}^{-1}$ intravenously for $48 \mathrm{hr}$ postoperatively. Plasma levels of the proinflammatory markers C-reactive protein (CRP), fibrinogen (FBG), tumour necrosis factor (TNF)- $\alpha$, interleukin (IL)- 6 and monocyte chemoattractant protein (MCP)-I, and the antiinflammatory marker IL-10, were compared before and after surgery.

Results: Ninety-six hours after start of surgery, plasma levels of FBG had more than doubled $(2.2 \pm 0.5$-fold increase, $P<$ $0.0001)$. Overall, FBG formation was significantly increased in the AMIO group $(P=0.048)$. Monocyte chemoattractant protein I secretion transiently increased four hours after start of surgery $(6.6 \pm 4.5$-fold increase) but rapidly declined thereafter, $(P<0.000 \mathrm{I})$. There was a trend toward higher MCP-I plasma concentrations in the AMIO group $(P=0.13)$. The plasma levels of CRP, TNF- $\alpha$, IL- 6 and II- I 0 changed significantly over time, but were not altered by AMIO treatment.

Conclusion: In the inflammatory response induced by cardiac surgery with $C P B$, our data suggest that AMIO treatment is associated with a selective trend toward proinflammatory actions.
CAN J ANESTH $2007 / 54: 4 /$ pp 262-268

Objectif : On a démontré que l'amiodarone (AMIO), un médicament anti-arythmique très utilisé, réduit l'incidence de fibrillation auriculaire après la chirurgie cardiaque et qu'il exerce une action immunomodulatrice in vitro ainsi que des effets pro-inflammatoires in vivo. Cette étude a observé les propriétés immunomodulatrices de l'AMIO dans la réaction inflammatoire provoquée par la chirurgie cardiaque avec circulation extracorporelle (CEC).

Méthode: Dans cette étude à double insu et contrôlée par placebo, vingt patients devant subir un pontage aortocoronarien ont été randomisés à recevoir oralement soit un placebo, soit de I'AMIO $600 \mathrm{mg} \cdot \mathrm{jour}^{-1}$ les sept jours précédant la chirurgie et 45 $\mathrm{mg} \cdot \mathrm{h}^{-1}$ en intraveineux durant les $48 \mathrm{~h}$ suivant l'opération. Les niveaux plasmatiques des marqueurs pro-inflammatoires suivants ont été comparés avant et après l'opération : protéine C-réactive $(C R P)$, fibrinogène (FBG), facteur nécrosant des tumeurs (TNF)- $\alpha$, interleukine (IL)-6 et protéine chimioattractive monocytaire (MCPI), et le marqueur anti-inflammatoire IL-I0.

Résultats: Les niveaux plasmatiques de FBG avaient plus que doublé $96 \mathrm{~h}$ après le début de la chirurgie (augmentation par 2,2 \pm 0,5 fois, $P<0,000 I$ ). De façon générale, la formation de FBG s'est accrue de façon significative dans le groupe $A M I O(P=0,048)$. La sécrétion de la MCP-I a momentanément augmenté quatre heures après le début de la chirurgie (de 6,6 \pm 4,5 fois), mais a rapidement diminué ensuite $(P<0,000 I)$. Une tendance vers des concentrations plasmatiques de $M C P$ - I plus élevées a été observée dans le groupe AMIO $(P=0,13)$. Les niveaux plasmatiques de

From the Departments of Cardiology, ${ }^{*}$ Cardiac-Thoracic Surgery, $\dagger$ and Cardiac-Thoracic Anesthesia, $\ddagger$ and the Core Unit for Medical Statistics and Informatics Section of Medical Statistics, $\$$ Medical University of Vienna, Austria.

Address correspondence to: Dr. Georg Delle Karth, Universitaetsklinik fuer Innere Medizin II/ Kardiologie, Medizinische Universitaet,

Wien, Waehringer Guertel 18-20, 1090 Wien, Austria. Phone: ++ 43-1-40400 -4615; Fax: ++43-1-40400 -4216;

E-mail: georg.delle-karth@meduniwien.ac.at

Supported by the "Austrian Fonds zur Foerderung der Wissenschaftlichen Forschung" (Grant P 15152) ISRCTN33778807.

Accepted for publication January 12, 2007.

Revision accepted January 22, 2007. 
CRP, TNF- $\alpha, I L-6$ et IL-10 se sont modifiés de façon significative durant le temps de l'étude, mais le traitement à l'AMIO ne les a pas influencés.

Conclusion : Dans le cas de la réaction inflammatoire provoquée par une chirurgie cardiaque avec CEC, nos données suggèrent que le traitement à l'AMIO est associé à une tendance sélective vers des propriétés pro-inflammatoires.

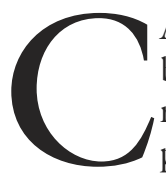

ARDIAC surgery with cardiopulmonary bypass $(\mathrm{CPB})$ induces an inflammatory response that has been implicated in the pathogenesis of postoperative complications. ${ }^{1,2}$ Amiodarone (AMIO), the single most commonly used antiarrhythmic drug in the cardiac-surgical setting, has been used to effectively reduce the incidence of atrial fibrillation after cardiac surgery. ${ }^{3}$ Numerous studies have ascertained that it does not increase mortality in highly compromised cohorts as do other antiarrhythmic substances. ${ }^{4,5}$ It has also recently been shown that AMIO inhibits the production of tumour necrosis factor (TNF)- $\alpha$ in lipopolysaccharide (LPS)stimulated human mononuclear cells in vitro. ${ }^{6}$ In contrast, earlier studies also suggest that AMIO enhances the cytokine release in mouse alveolar macrophages via activation of protein kinase C. ${ }^{7}$ Furthermore, the use of AMIO has been associated with pulmonary, thyroid and hepatic toxicities that are at least partly mediated by inflammatory processes. ${ }^{8-10}$ Thus, the immunomodulatory effects of this frequently used drug are unclear. Potential antiinflammatory effects might abrogate complications induced by the systemic inflammatory response after cardiac surgery. On the other hand, potential proinflammatory properties could potentiate the inflammatory cycle and may therefore contribute to a complicated postoperative course.

The aim of the present study was to investigate the immunomodulating properties of AMIO in patients after cardiac surgery with the use of CPB. We tested the null hypothesis that there would be no difference in the postoperative inflammatory response between AMIO- and placebo-treated patients. We determined plasma levels of the proinflammatory markers C-reactive protein $(\mathrm{CRP})$, fibrinogen (FBG), TNF- $\alpha$, interleukin (IL)-6 and monocyte chemoattractant protein (MCP)-1 as well as the antiinflammatory marker IL10 before and after cardiac surgery.

\section{Patients and methods}

Study design

This prospective, randomized, double-blind study was conducted at the Vienna General Hospital / Medical
University, Austria, between April 2002 and March 2004. The study was approved by the local ethical committee, and all patients gave written informed consent. Patients over 40 and under $75 \mathrm{yr}$ of age undergoing non-emergent coronary artery bypass surgery with $\mathrm{CPB}$ were eligible for the study. Exclusion criteria were: a history of adverse events to AMIO; concurrent treatment with AMIO within four months of enrolment; the use of antiarrhythmic therapy other than beta-receptor blockers, calcium channel blockers or digitalis; a CRP concentration above $1.0 \mathrm{mg} \cdot \mathrm{dL}^{-1}$; a serum asparate aminotransferase or an alanine aminotransferase concentration four times the upper limit; child-bearing potential; an untreated thyroid dysfunction $\left(\mathrm{TSH}<0.01,>10 \mathrm{miU} \cdot \mathrm{mL}^{-1}\right)$; chronic renal failure (serum creatinine $>114 \mu \mathrm{mol} \cdot \mathrm{L}^{-1}$ ); an ejection fraction $<30 \%$ (determined either by nuclear, left fluorescence ventriculography or echocardiography); diabetes mellitus; unstable angina; a resting heart rate of less than 50 beats. $\mathrm{min}^{-1}$; an active infection; malignancy; and chronic atrial fibrillation.

Patients were randomly assigned to receive placebo $(n=12)$ or AMIO $600 \mathrm{mg} \cdot \mathrm{day}^{-1}$ for seven days orally before and $45 \mathrm{mg} \cdot \mathrm{hr}^{-1}$ iv for $48 \mathrm{hr}$ after the start of surgery $(n=10)$. Two patients in the AMIO group had to be excluded when informed consent was withdrawn.

\section{Study procedures}

A total of 1,211 patients scheduled for elective cardiac surgery were screened during the study period. Among 25 eligible patients, 22 patients were willing to consent and fulfilled all inclusion criteria. These patients were randomized using block randomization in groups of ten. Identical-appearing placebo/AMIO tablets and vials were randomly numbered by the manufacturer, and the list of number allocations was handed over after the end of the study. Preoperative testing included medical history and physical examination, laboratory testing (hematology, chemistry) and electrocardiogram. Anesthesia and CPB management was conducted according to a standardized protocol. Induction of anesthesia was achieved and maintained with propofol and fentanyl. Hemodynamics were monitored invasively with an indwelling arterial line. A urinary catheter with a tip thermistor was inserted. Cardiopulmonary bypass was achieved using a roller pump adjusted to $120 \%$ of the calculated cardiac index of $2 \mathrm{~L} \cdot \mathrm{min}^{-1} \cdot \mathrm{m}^{2}$, silicone circuits and a membrane oxygenator. The CPB (circuit volume $1600 \mathrm{~mL}$ ) was filled with crystalloids. Heparin was used for anticoagulation during CPB at an initial dose of $400 \mathrm{U} \cdot \mathrm{kg}^{-1}$ supplemented with additional heparin to maintain an 
TABLE I Baseline clinical data

\begin{tabular}{lll}
\hline & $\begin{array}{l}\text { Placebo Group } \\
(n=12)\end{array}$ & $\begin{array}{l}\text { AMIO Group } \\
(n=8)\end{array}$ \\
\hline Age $(\mathrm{yr})$ & $62.9 \pm 8$ & $61.4 \pm 9$ \\
Male $(n, \%)$ & $10(83.3 \%)$ & $7(87.5 \%)$ \\
prior MI $(n, \%)$ & $6(50 \%)$ & $4(50 \%)$ \\
$\#$ VD & & \\
2 VD $(n, \%)$ & $4(33.3 \%)$ & $2(25 \%)$ \\
3 VD $(n, \%)$ & $8(66.7 \%)$ & $6(75 \%)$ \\
CCS angina class & & $1(12.5 \%)$ \\
CCS 0 $(n ; \%)$ & $1(8.3 \%)$ & $2(25 \%)$ \\
CCS I $(n ; \%)$ & $4(33.3 \%)$ & $4(50 \%)$ \\
CCS II $(n ; \%)$ & $4(33.3 \%)$ & $1(12.5 \%)$ \\
CCS III $(n ; \%)$ & $3(25 \%)$ & \\
NYHA functional class & & $4(50 \%)$ \\
NYHA I $(n ; \%)$ & $5(41.7 \%)$ & $3(37.5 \%)$ \\
NYHA II $(n ; \%)$ & $5(41.7 \%)$ & $112.5 \%)$ \\
NYHA III $(n ; \%)$ & $1(8.3 \%)$ & $57.4 \pm 7$ \\
LVEF $(\%)$ & $53.5 \pm 6$ & C $\%$
\end{tabular}

$\mathrm{MI}=$ myocardial infarction $; \mathrm{VD}=$ vessel disease $; \mathrm{CCS}=$ Canadian Cardiovascular Society; NYHA = New York Heart Association; $\mathrm{LVEF}=$ left ventricular ejection fraction.

TABLE II Periprocedural data

\begin{tabular}{|c|c|c|}
\hline & $\begin{array}{l}\text { Placebo } \\
\text { Group } \\
(n=12)\end{array}$ & $\begin{array}{l}\text { AMIO } \\
\text { Group } \\
(n=8)\end{array}$ \\
\hline SAPS II score on ICU admission & $21.5(7-36)$ & $20(15-23)$ \\
\hline (median, range) \# of grafts & $2.5 \pm 0.6$ & $2.25 \pm 0.7$ \\
\hline $1(n ; \%)$ & $1(8.3 \%)$ & $1(12.5 \%)$ \\
\hline $2(n ; \%)$ & $4(33.3 \%)$ & $4(50 \%)$ \\
\hline $3(n ; \%)$ & $7(58.3 \%)$ & $3(30 \%)$ \\
\hline IMA graft (\# patients) & 11 & 8 \\
\hline $\mathrm{CPB}$ time $(\mathrm{min})$ & $78.8 \pm 15.5$ & $79.6 \pm 17.1$ \\
\hline Aortic cross clamp time (min) & $53.8 \pm 11.6$ & $44.1 \pm 11.6$ \\
\hline \# packed red cells (units, median, range) & $0(0-2)$ & $0(0-2)$ \\
\hline Lowest hematocrit during operation (\%) & $27.9 \pm 3.8$ & $26.4 \pm 2.7$ \\
\hline Defibrillation on reperfusion $(n ; \%)$ & $1(8.3 \%)$ & $1(12.5 \%)$ \\
\hline Atrial fibrillation $(n, \%)$ & $4(33.3 \%)$ & $3(37.5 \%)$ \\
\hline Atrial fibrillation (day, median, range) & $3.5(0-5)$ & $2(1-3)$ \\
\hline Pacing required (no. patients, \%) & $2(16.7 \%)$ & $3(37.5 \%)$ \\
\hline Postoperative sepsis & $3(25 \%)$ & 0 \\
\hline Mechanical ventilation (days) & $1(1-1)$ & $1(1-1)$ \\
\hline ICU stay (days; median, range) & $2(1-4)$ & $2(1-4)$ \\
\hline Hospital stay (days; median, range) & $10(9-17)$ & $9(8-9)$ \\
\hline
\end{tabular}

activated clotting time of $>400 \mathrm{sec}$. Heparin was neutralized with protamin sulfate after separation from $\mathrm{CPB}$. During the operative procedure, all patients received aprotinin (Trasylol, 50,000 IE $\cdot \mathrm{kg}^{-1}$, Bayer, Leverkusen, Germany). Bypass temperature was kept between 36 and $37^{\circ} \mathrm{C}$, and cold antegrade and retrograde cardioplegia were used in all patients.

\section{Blood sampling and biochemical assays}

C-reactive protein and FBG plasma levels were determined at baseline and at four, 24, 48, 72, $96 \mathrm{hr}$ after start of surgery. Tumour necrosis factor- $\alpha$, IL- 6, IL-10 and MCP-1 plasma levels were assessed at baseline, after aortic cross clamping and at one, four, 24, 48 $\mathrm{hr}$ after start of surgery. All samples were centrifuged immediately at $4^{\circ} \mathrm{C}$ and stored at $-70^{\circ} \mathrm{C}$ until analysis.

C-reactive protein was assessed by the turbidimetric method on a Hitachi 917 analyzer (Roche Diagnostics, Vienna, Austria); FBG by the Clauss method on the STA clinical analyzer (Roche diagnostics, Vienna, Austria). Tumour necrosis factor- $\alpha$ (R\&D Systems, Wiesbaden, Germany), IL-6, IL-10 (Bender MedSystems, Vienna, Austria) and MCP-1 (Bender MedSystems, Vienna, Austria) levels in plasma were determined by commercially available double- sided, enzyme-linked immunoassays.

\section{Analysis}

Generalized least squares estimation equations (Rpackage "Design") were used to compare over time and between groups the $\mathrm{x}$-fold change from baseline for the mediator responses CRP, FBG, TNF- $\alpha$, IL- 6 , IL-10, and MCP-1. Time and group were modeled as factor variable. For TNF- $\alpha$, IL-6, IL-10, and MCP-1 the analyses comprise the time points 0.1 , one, four, 24 and $48 \mathrm{hr}$ after aortic cross clamping. For CRP and FBG time points one, four, 24, 48, 72 and $96 \mathrm{hr}$ were analyzed. No multiplicity adjustment was performed. We choose the prototypical acute phase protein CRP that is routinely measured in the postoperative course at our institution to determine the sample size. Our clinical observation showed a standard deviation of approximately $25 \%$ in peak CRP concentrations after cardiac surgery. We assumed that a difference of $30 \%$ between groups would be a clinically important result. The necessary sample size for $P>0.05$ and power 0.8 was two groups of 11 . Results are expressed as a mean \pm standard deviation if normally distributed. Medians and range were used when the distribution was skewed. Categorical values were compared using the $\chi^{2}$ test and Fisher's exact test as appropriate. A $P<$ 0.05 was considered significant.

\section{Results}

\section{Patient characteristics}

All patients with outcome data were analyzed according to the intention-to-treat principle. A total of 20 patients were available for analysis. Baseline clinical data are given in Table I. Periprocedural data are presented in Table II. Three patients in the placebo group developed postoperative sepsis. The foci were sternal 
TABLE III Baseline values

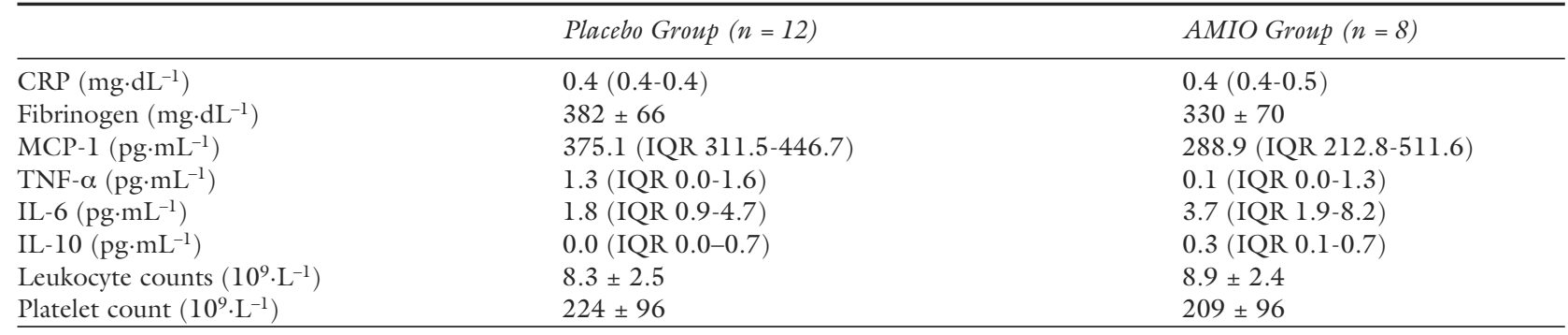

$\mathrm{AMIO}=$ amiodarone; $\mathrm{CRP}=\mathrm{C}$-reactive protein; $\mathrm{MCP}-1=$ monocyte chemoattractant protein; $\mathrm{TNF}=$ tumour necrosis factor; $\mathrm{IL}=$ interleukin; IQR = interquartile range.
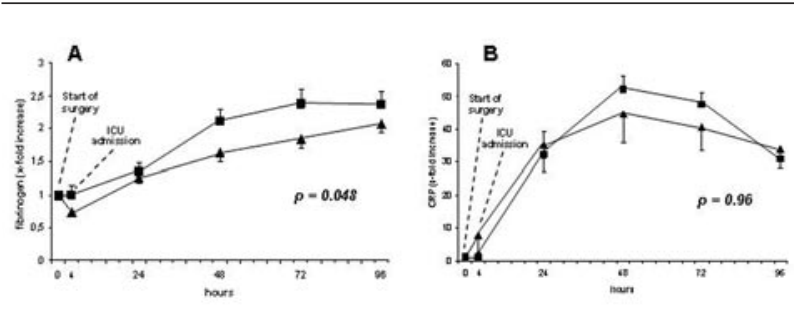

FIGURE 1 Plasma levels of C-reactive protein and fibrinogen are shown as a function of time in post-cardiac surgery patients receiving either placebo (triangles) or amiodarone (squares). Data are expressed as mean \pm SEM. Probability values represent generalized least squares estimation equations (R-package "design") between groups.

osteomyelitis with staphylococci in two patients and a culture-negative pneumonia in the third patient. One patient in the placebo group was found to suffer from diabetes after inclusion in the study, but his data were analyzed according to the intention-to-treat principle. There were no deaths in either group.

\section{Mediator responses in placebo and AMIO-treated patients}

Baseline laboratory values are presented in Table III. Ninety-six hours after start of surgery, plasma levels of FBG had more than doubled $(2.2 \pm 0.5$-fold increase $)$ compared to baseline. Accordingly, the influence of the factor time was statistically significant $(P<$ $0.0001)$. Overall, FBG formation was significantly increased in the AMIO group ( $P=0.048$; Figure 1A). Table 4 shows the estimates and $95 \%$ confidence limits for least squares estimates of the difference between the AMIO and placebo group. MCP-1 secretion transiently increased four hours after start of surgery $(6.6$ \pm 4.5 -fold increase) but rapidly declined thereafter,
TABLE IV

\begin{tabular}{lllll}
\hline & \multicolumn{5}{c}{ 95\% confidence limits } \\
Outcome variable & Estimate & Lower limit & Upper limit & P-value \\
\hline Fibrinogen $\left(\mathrm{mg} \cdot \mathrm{dL}^{-1}\right)$ & 0.33 & 0.0035 & 0.66 & 0.048 \\
MCP-1 $\left(\mathrm{pg} \cdot \mathrm{mL}^{-1}\right)$ & 0.94 & -0.28 & 2.16 & 0.13 \\
CRP $\left(\mathrm{mg} \cdot \mathrm{dL}^{-1}\right)$ & 0.39 & -12.2 & 12.8 & 0.96 \\
TNF- $\alpha\left(\mathrm{pg} \cdot \mathrm{mL}^{-1}\right)$ & 0.20 & -0.65 & 1.04 & 0.65 \\
IL-6 $\left(\mathrm{pg} \cdot \mathrm{mL}^{-1}\right)$ & -5.54 & -20.7 & 9.65 & 0.47 \\
IL-10 $\left(\mathrm{pg} \cdot \mathrm{mL}^{-1}\right)$ & 2.85 & -1.90 & 7.60 & 0.24 \\
\hline
\end{tabular}

Least square estimates, $95 \%$ confidence limits and $P$-values from the generalized estimation equation analyses. $\mathrm{MCP}-1=$ monocyte chemoattractant protein; $\mathrm{CRP}=\mathrm{C}$-reactive protein; $\mathrm{TNF}=$ tumour necrosis factor; $\mathrm{IL}=$ interleukin.

indicating a statistically significant influence of time $(P$ $<0.0001$; Figure 2B).

C-reactive protein plasma concentrations peaked ( $47 \pm 24$-fold increase) $48 \mathrm{hr}$ after start of surgery and slowly decreased thereafter $(P<0.0001$; Figure 1B). Tumour necrosis factor- $\alpha$ levels increased four hours $(3.3 \pm 2.8$-fold increase $)$ after the start of surgery but rapidly normalized thereafter $(P=0.0008$; Figure $2 \mathrm{~A})$. Likewise, IL-6 plasma levels peaked four hours after start of surgery ( $49 \pm 43$-fold increase) but were still increased $30 \pm 26$-fold $24 \mathrm{hr}$ after surgery $(P<$ 0.0001 ; Figure 2C). Interleukin-10 plasma concentrations showed an early peak one hour after start of surgery ( $17 \pm 22$-fold increase) and decreased rapidly thereafter $(P<0.0001$; Figure 2D). C-reactive protein, TNF- $\alpha$, MCP1, IL- 6 and Il-10 plasma levels did not significantly differ between placebo- and AMIOtreated patients (Table IV).

\section{Discussion}

Cardiac surgery with CPB induces an inflammatory response that may lead to tissue injury and, as a consequence, to a complicated postoperative course. ${ }^{1,2}$ The use of AMIO, the single most used antiarrhythmic 

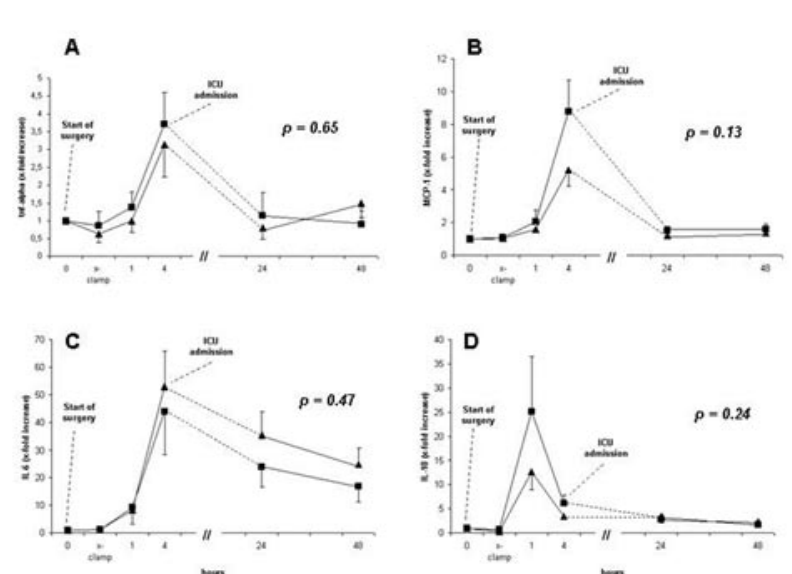

FIGURE 2 Significant changes over time but not between groups were observed for tumour necrosis factor- $\alpha$, monocyte chemoattractant protein-1 (MCP), interleukin (IL)-6 and IL- 10 plasma levels in post-cardiac surgery patients receiving either placebo (triangles) or amiodarone (squares), for seven days before and $48 \mathrm{hr}$ after start of surgery. Data are expressed as mean \pm SEM.

drug in the cardiac-surgical and intensive care unit setting, ${ }^{3,11,12}$ has been associated with blunted TNF- $\alpha$ production in stimulated monocytes in vitro, ${ }^{6}$ but also with pulmonary, thyroid and hepatic inflammation in clinical settings. ${ }^{8-10}$ Our data do not support the in vitro data of an isolated antiinflammatory potential of AMIO, but rather a selective trend toward proinflammatory actions of this drug in the inflammatory response induced by cardiac surgery with $\mathrm{CPB}$.

We found that a treatment of stable cardiac surgical patients with AMIO for seven days before and 48 $\mathrm{hr}$ after start of surgery significantly enhanced plasma levels of FBG. Fibrinogen plays a crucial role in the coagulation system and in tissue repair. ${ }^{13}$ Its production is regulated by a complex cytokine network. ${ }^{13}$ Elevated levels of FBG are not only a marker for the severity of the inflammatory response but are also associated with an increased risk of saphenous vein graft stenosis and occlusion. ${ }^{14}$ In addition, the trend toward enhancement of $\mathrm{MCP}-1$ production indicates a potential selective proinflammatory effect of AMIO after cardiac surgery. Monocyte chemoattractant protein-l is a prototypic inflammatory chemokine, which targets monocytes, $\mathrm{T}$ lymphocytes, and other cells expressing the $\mathrm{C}-\mathrm{C}$ chemokine receptor. ${ }^{15} \mathrm{In}$ addition to providing chemotactic cues for the recruitment of monocytes from the bloodstream to the tissue, MCP$\mathrm{l}$ is also responsible for monocyte activation and oxidative burst. ${ }^{16}$ It has been shown that in children, higher MCP-1 plasma levels after cardiac surgery were associated with prolonged inotropic support and with higher re-operation rates. ${ }^{17}$

In accordance with our data, earlier studies on animal models have shown that AMIO is able to induce proinflammatory mediators in pulmonary alveolar macrophages by activating protein kinase C.? Activation of protein kinase $\mathrm{C}$ plays a crucial role in the development of the systemic inflammatory response and multi-organ dysfunction. ${ }^{18}$ However, increases in plasma levels were not seen in all proinflammatory markers, suggesting that AMIO exerts a far more complex potential proinflammatory action than simply enhancing one proinflammatory or blocking one antiinflammatory effector.

The potential AMIO-associated trend toward enhancement of the inflammatory response is in line with a previous study that reported an increase in proinflammatory mediators after long-term AMIO treatment in patients with ischemic cardiomyopathy. ${ }^{19}$ Interestingly, increased proinflammatory markers were not seen in patients with dilated cardiomyopathy. This observation could lead to the assumption that AMIO in therapeutic dose ranges does not induce an inflammatory response per se, but may enhance the inflammatory cycle caused by other triggers such as atherosclerosis or, as in our study, cardiac surgery. Accordingly, AMIO-induced lung toxicity was primarily observed in surgical patients with high respirator settings, ${ }^{20}$ known to potentially induce a systemic inflammatory response. However, the significance of our finding in clinical terms remains unclear.

Our results do not support the in vitro effects of AMIO on TNF- $\alpha$ production by LPS stimulated monocytes. ${ }^{6}$ The reasons are not clear, but include the complex pathophysiology of the inflammatory response syndrome after cardiac surgery with $\mathrm{CPB}$. In addition to gut-released endotoxin, ${ }^{21}$ various other triggers such as the surgical trauma itself, ${ }^{22}$ blood contact with the non-physiological surfaces of the extracorporal circuit, ${ }^{23}$ and myocardial hypoxia induced by the $\mathrm{CPB}$ and aorta cross clamping also contribute to the pathogenesis of the inflammatory reaction to $\mathrm{CPB} .{ }^{24}$

Taking into consideration the pattern of cytokine production after cardiac surgery, our data are comparable with those of earlier studies. ${ }^{25-32}$ However, the absolute values, especially the TNF- but also the IL-6 concentrations, were lower in our patients compared to those in other series. Besides differences in patient populations, possible explanations include the routine use of aprotinin, which has been shown to blunt the 
cytokine response in some studies while having no effect in others. ${ }^{29,30}$ Furthermore, differences in the biocompatibility of various $\mathrm{CPB}$-circuits, $\mathrm{CPB}$ flow and duration, different cardioplegia-solutions, and differences in anesthesia protocols may have influenced the amount of cytokine release. While these factors were controlled in the present study, they preclude comparisons in absolute terms.

Our study has several limitations. First, because of the rather small sample size the generalizability of our findings may be limited. It should be acknowledged, however that we used very stringent inclusion criteria and highly standardized treating procedures. Further, differences in the plasma levels of TNF- $\alpha$ and IL- 6 at baseline might have influenced the study results. Still, since we calculated the data as individual changes, these differences at baseline should be largely abrogated. Drawing clinical conclusions was certainly beyond the scope of our study, and the mechanisms by which AMIO exerts its immunomodulatory actions cannot be obtained from our data.

Our study is the first to provide data on the potential proinflammatory profile of AMIO in an in vivo model, as suggested by previous in vitro and in vivo studies. In cardiac surgery with CPB, AMIO treatment was associated with a significantly higher formation in FBG and a trend toward higher MCP-1 generation compared with placebo-treated patients. To further elucidate the inflammatory effects of AMIO in cardiac surgery, larger randomized trials are warranted.

\section{References}

1 Westaby S. Organ dysfunction after cardiopulmonary bypass. A systemic inflammatory reaction initiated by the extracorporeal circuit. Intensive Care Med 1987; 13: 89-95.

2 Casey LC. Roles of cytokines in the pathogenesis of cardiopulmonary-induced multisystem organ failure. Ann Throrac Surg 1993; 56(5 Suppl): S92-6.

3 Daoud EG, Strickberger SA, Man KC, et al. Preoperative amiodarone as prophylaxis against atrial fibrillation after heart surgery. N Engl J Med 1997; 337: 1785-91.

4 Singh SN, Fletcher RD, Fisher SG, et al. Amiodarone in patients with congestive heart failure and asymptomatic ventricular arrhythmia. Survival Trial of Antiarrhythmic Therapy in Congestive Heart Failure. N Engl J Med 1995; 333: 77-82.

5 Bardy GH, Lee KL, Mark DB, et al.; Sudden Cardiac Death in Heart Failure Trial (SCD-HeFT) Investigators. Amiodarone or an implantable cardioverter-defibrillator for congestive heart failure. $\mathrm{N}$ Engl J Med 2005; 352: 225-37.
6 Matsumori A, Ono K, Nishio R, Nose $\Upsilon$, Sasayama S. Amiodarone inhibits production of tumor necrosis factor- $\alpha$ by human mononuclear cells: a possible mechanism for its effect in heart failure. Circulation 1997; 72: 1386-9.

7 Futamura $\Upsilon$. Effect of amiodarone on cytokine release and on enzyme activities of mouse alveolar macrophages, bone marrow macrophages, and blood monocytes. J Toxicol Sci 1996; 21: 125-34.

8 Ashrafian $H$, Davey $P$. Is amiodarone an underrecognized cause of acute respiratory failure in the ICU? Chest 2001; 120: 275-82.

9 Basaria S, Cooper DS. Amiodarone and the thyroid. Am J Med 2005; 118: 706-14.

10 Lewis JH, Mullick F, Ishak KG, et al. Histopathologic analysis of suspected amiodarone hepatotoxicity. Hum Pathol 1990; 21: 59-67.

11 Delle Karth G, Geppert A, Priglinger U, et al. Amiodarone versus diltiazem for rate control in critically ill patients with atrial tachyarrhythmias. Crit Care Med 2001; 29:1149-53.

12 Guglin $M$. Intravenous amiodarone: offender or bystander? Crit Care Med 2005; 33: 245-6.

13 Mosesson MW, Siebenlist KR, Meh DA. The structure and biological features of fibrinogen and fibrin. Ann $\mathrm{N}$ Y Acad Sci 2001; 936: 11-30.

14 Hicks RC, Golledge J, Mir-Hasseine R, Powell JT. Vasoactive effects of fibrinogen on saphenous vein. Nature 1996; 29: 379: 818-20.

15 Daly C, Rollins BJ. Monocyte chemoattractant protein-1 (CCL2) in inflammatory disease and adaptive immunity: therapeutic opportunities and controversies. Microcirculation 2003; 10: 247-57.

16 Rollins BJ, Walz A, Baggiolini M. Recombinant human MCP-1/JE induces chemotaxis, calcium flux, and the respiratory burst in human monocytes. Blood 1991; 78: 1112-6.

17 Lotan D, Zilberman D, Dagan O, et al. Beta-chemokine secretion patterns in relation to clinical course and outcome in children after cardiopulmonary bypass: continuing the search to abrogate systemic inflammatory response. Ann Thorac Surg 2001; 71: 233-7.

18 Arbabi S, Maier RV. Mitogen-activated protein kinases. Crit Care Med 2002; 30(Suppl): S74-9.

19 Oral H, Fisher SG, Fay WP, Singh SN, Fletcher RD, Morady $F$. Effects of amiodarone on tumor necrosis factor-alpha levels in congestive heart failure secondary to ischemic or idiopathic dilated cardiomyopathy. Am J Cardiol 1999; 83: 388-91.

20 Saussine M, Colson P, Alauzen M, Mary H. Postoperative acute respiratory distress syndrome. A complication of amiodarone associated with 100 per cent oxygen ventilation. Chest 1992; 102: 980-1. 
21 Riddington DW, Venkatesh B, Boivin CM, et al. Intestinal permeability, gastric intramucosal $\mathrm{pH}$ and systemic endotoxemia in patients undergoing cardiopulmonary bypass. JAMA 1996; 275: 1007-12.

22 Gu YJ, Mariani MA, Boonstra PW, Grandjean JG, van Oeveren $W$. Complement activation in coronary artery bypass grafting patients without cardiopulmonary bypass: the role of tissue injury by surgical incision. Chest 1999; 116: 892-8.

23 Giomarelli P, Scolletta S, Borrelli E, Biagioli B. Myocardial and lung injury after cardiopulmonary bypass: role of interleukin (IL)-10. Ann Thorac Surg 2003; 76: 117-23.

24 Wan S, DeSmet, JM, Barvais L, Goldstein M, Vincent $J L$, LeClerc JL. Myocardium is a major source of proinflammatory cytokines in patients undergoing cardiopulmonary bypass. J Thorac Cardiovasc Surg 1996; 112: 806-11.

25 Kristof AS, Magder S. Low systemic vascular resistance state in patients undergoing cardiopulmonary bypass. Crit Care Med 1999; 27: 1121-7.

26 Johnson MR. Low systemic vascular resistance after cardiopulmonary bypass: are we any closer to understanding the enigma? Crit Care Med 1999; 27: 1048-9.

27 Cremer J, Martin M, Redl H, et al. Systemic inflammatory response syndrome after cardiac operations. Ann Thorac Surg 1996; 61: 1714-20.

28 Bourbon A, Vionnet $M$, Leprince $P$, et al. The effect of methylprednisolone treatment on the cardiopulmonary bypass-induced systemic inflammatory response. Eur J Cardiothorac Surg 2004; 26: 932-8.

29 Schmartz D, Tabardel $\Upsilon$, Preiser JC, et al. Does aprotinin influence the inflammatory response to cardiopulmonary bypass in patients? J Thorac Cardiovasc Surg 2003; 125: 184-90.

30 Hill GE, Alonso A, Spurzem JR, Stammers AH, Robbins $R A$. Aprotinin and methylprednisolone equally blunt cardiopulmonary bypass-induced inflammation in humans. J Thorac Cardiovasc Surg 1995; 110: 165862.

31 Rathmell JP, Prielipp RC, Butterworth JF, et al. A multicenter, randomized, blind comparison of amrinone with milrinone after elective cardiac surgery. Anesth Analg 1998; 86: 683-90.

32 Verrier ED, Shernan SK, Taylor KM, et al.; PRIMO$C A B G$ Investigators. Terminal complement blockade with pexelizumab during coronary artery bypass graft surgery requiring cardiopulmonary bypass: a randomized trial. JAMA 2004; 291: 2319-27. 